\title{
Mesorhizobium septentrionale sp. nov. and Mesorhizobium temperatum sp. nov., isolated from Astragalus adsurgens growing in the northern regions of China
}

Correspondence Wen Xin Chen wenxin_chen@263.net
Jun-Lian Gao, ${ }^{1,2,3}$ Sarah Lea Turner, ${ }^{3}$ Feng Ling Kan, ${ }^{1}$ En Tao Wang, ${ }^{1,4}$ Zhi Yuan Tan, ${ }^{5}$ Yu Hui Qiu, ${ }^{1}$ Jun Gu, ${ }^{1}$ Zewdu Terefework, ${ }^{2}$ J. Peter W. Young, ${ }^{3}$ Kristina Lindström ${ }^{2}$ and Wen Xin Chen $^{1}$

${ }^{1}$ Key Laboratory of Agro-Microbial Resources and Application, Ministry of Agriculture of China, College of Biological Sciences, China Agricultural University, Beijing 100094, China

${ }^{2}$ Department of Applied Chemistry and Microbiology, Biocenter 1, PO Box 56, FIN-00014, University of Helsinki, Finland

${ }^{3}$ Department of Biology, University of York, PO Box 373, York Y01 5YW, UK

${ }^{4}$ Departamento de Microbiología, Escuela Nacional de Ciencias Biológicas, Instituto Politécnico Nacional, México D.F. 11340, Mexico

${ }^{5}$ Department of Molecular Genetics, College of Agronomy, South China Agricultural University, Guangzhou 510642, China

Ninety-five rhizobial strains isolated from Astragalus adsurgens growing in the northern regions of China were classified into three main groups, candidate species I, II and III, based on a polyphasic approach. Comparative analysis of full-length 16S rRNA gene sequences of representative strains showed that candidate species I and II were Mesorhizobium, while candidate species III, which consisted of non-nodulating strains, was closely related to Agrobacterium tumefaciens. The phylogenetic relationships of the three candidate species and some related strains were also confirmed by the sequencing of $g \ln A$ genes, which were used as an alternative chromosomal marker. The DNA-DNA relatedness was between $11 \cdot 3$ and $47 \cdot 1 \%$ among representative strains of candidate species I and II and the type strains of defined Mesorhizobium species. Candidate III had DNA relatedness of between $4 \cdot 3$ and $25 \cdot 2 \%$ with type strains of Agrobacterium tumefaciens and Agrobacterium rubi. Two novel species are proposed to accommodate candidate species I and II, Mesorhizobium septentrionale sp. nov. (type strain, SDW014 ${ }^{\top}=\mathrm{CCBAU} 11014^{\top}=\mathrm{HAMBI} 2582^{\top}$ ) and Mesorhizobium temperatum sp. nov. (type strain, SDW018 ${ }^{\top}=$ CCBAU $11018^{\top}=\mathrm{HAMBI} 2583^{\top}$ ), respectively. At least two distinct $\operatorname{nod} A$ sequences were identified among the strains. The numerically dominant nod $A$ sequence type was most similar to that from the Mesorhizobium tianshanense type strain and was identified in strains belonging to the two novel species as well as other, as yet, undefined genome types. Host range studies indicate that the different nodA sequences correlate with different host ranges. Further comparative studies with the defined Agrobacterium species are needed to clarify the taxonomic identity of candidate species III.
Published online ahead of print on 14 May 2004 as DOI 10.1099/ ijs.0.02840-0.

The GenBank/EMBL/DDBJ accession numbers for the 16S rRNA gene sequences obtained in this work are AF508207, AF508208 and AF508209 for strains SDW014 ${ }^{\top}$, SDW018 ${ }^{\top}$ and SDW052, respectively. Those for the partial $g / n A$ gene sequences determined in this study are AJ579875-AJ579885.

A phylogenetic tree is available as supplementary material in IJSEM Online.

\section{INTRODUCTION}

Plants within the family Leguminosae are agriculturally important and are planted worldwide for many purposes, including food and fodder production, as green manures, as soil coverage to reduce erosion, as herbal medicines and in gardening/landscaping. It has been shown that different plants in the same geographical region can share the same rhizobial group for nodulation; examples are Mesorhizobium tianshanense (Chen et al., 1995), Mesorhizobium plurifarium 
(de Lajudie et al., 1998) and Rhizobium hainanense (Chen et al., 1997). Conversely, the same plant species may associate with different rhizobial species; for example, soybean is nodulated by Bradyrhizobium japonicum, Bradyrhizobium liaoningense (Xu et al., 1995), Mesorhizobium tianshanense (Chen et al., 1995), Sinorhizobium fredii and Sinorhizobium xinjiangense (Chen et al., 1988; Peng et al., 2002) in different regions of China. However, the geographical ranges of host plants and microsymbionts are often restricted and rhizobial inocula are necessary in many cases when legumes are introduced into new areas (e.g. Sullivan et al., 1996). Considering the specificity of the symbiosis between rhizobia and their host plants and the adaptation of these bacteria to their environments, characterization of local isolates is important to explore these microbial resources and optimize legume use.

The genus Astragalus, consisting of 1500-2000 species, is one of the largest genera in the family Leguminosae and many species form nitrogen-fixing symbioses in association with root-nodule bacteria (Allen \& Allen, 1981). More than 70 species within this genus have been recorded in China and they have many economic uses; for example, in herbal medicine, as resources for honey production, as green manure (Li et al., 2000; Nagasawa et al., 2001; Shon et al., 2002) and for bioremediation (Sriprang et al., 2002). Different rhizobial groups have been identified among the nodule isolates from Astragalus species grown in China and other countries (Guo et al., 1999; Laguerre et al., 1997; Wang \& Chen, 1996; Wdowiak \& Malek, 2000). This lack of specificity is not universal: Astragalus sinicus, an important green manure in the southern regions of China, has been reported to nodulate almost exclusively with Mesorhizobium huakuii (Chen et al., 1991; Zhang et al., 2000). Among the Astragalus species used in China, Astragalus adsurgens has been planted over a vast area in desert and very dry regions to protect soils from wind erosion. In light of the important role of Astragalus adsurgens in improving the environment in the northern regions of China, we previously isolated rhizobia from nodules of this plant and characterized them using genetic methods, including rep-PCR fingerprinting, AFLP fingerprinting, and 16S rRNA and $23 S$ rRNA PCR-RFLP (Gao et al., 2001). This earlier work indicates that Astragalus adsurgens is nodulated by diverse rhizobial populations, including three dominant genomic groups (Gao et al., 2001). We have further characterized these strains using phenotypic analysis, DNA-DNA hybridization and sequencing of $16 \mathrm{~S}$ rRNA, glutamine synthetase $(g \ln A)$ and the symbiosis-associated $\operatorname{nodA}$ gene to explore, and better understand, the diversity and systematic relationships of the rhizobia associated with Astragalus adsurgens. The results indicate that two of the three dominant genomic groups are novel species of Mesorhizobium and the third is a non-symbiotic group related to Agrobacterium species.

\section{METHODS}

Bacterial strains. Strains used in this study are listed in Table 1. The 95 rhizobial strains from Astragalus adsurgens were obtained as part of an earlier study (Gao et al., 2001). Some reference strains representing the defined species or unnamed groups in Rhizobium, Mesorhizobium, Sinorhizobium and Agrobacterium and Escherichia coli $\mathrm{K}-12$ were included in different analyses. All the strains were kept in $20 \%(\mathrm{v} / \mathrm{v})$ glycerol at $-20^{\circ} \mathrm{C}$ and cultured in YMA medium (Vincent, 1970) at $28^{\circ} \mathrm{C}$.

Phenotypic characterization and numerical taxonomy. The 95 isolates from Astragalus adsurgens and 11 reference strains for related species were analysed using a total of 133 phenotypic characteristics as described previously (Gao et al., 1994). The Ssm coefficient and UPGMA (Sneath \& Sokal, 1973) were used for clustering analysis of phenotypic features.

Sequencing and phylogenetic analysis of 165 rRNA, gInA and nodA genes. To clarify the phylogenetic relationships, three strains, SDW014 ${ }^{\mathrm{T}}, \mathrm{SDW} 018^{\mathrm{T}}$ and SDW052, representing clusters 2, 11 and 6 (Table 1) identified by numerical taxonomy were used for sequence analyses of the 16S rRNA gene. These three strains and some others were used in the sequence analyses of $\operatorname{gn} A$ and $\operatorname{nod} A$ genes to further check the phylogenetic relationships and the diversity. The full-length $16 \mathrm{~S}$ rRNA genes were PCR-amplified and sequenced directly as described by Hurek et al. (1997). Internal gene fragments $(495 \mathrm{bp})$ of glutamine synthetase I $(g \ln A)$ were amplified and sequenced directly using the PCR primers and methods described by Turner \& Young (2000). Internal nodA gene sequences (470-476 bp) were amplified and sequenced directly using the PCR primers and methods of Zhang et al. (2000). The newly acquired sequences were aligned with other rhizobial sequences in the databases for the $16 \mathrm{~S}$ rRNA, glnA or nodA gene using CLUSTAL_X (Thompson et al., 1997), which was also used to construct and bootstrap (1000 replicates) the corresponding phylogenetic trees. All trees were visualized using TreeView (Page, 1996).

DNA base composition and DNA-DNA hybridization. Total DNA was extracted from each strain using the method of Marmur (1961). The G +C content of DNA was measured using the thermal denaturation method of Marmur \& Doty (1962) and E. coli K-12 as standard. DNA homology was determined using the spectrophotometric method of De Ley et al. (1970).

Symbiotic properties. Strains SDW $014^{\mathrm{T}}$ and $\mathrm{SDW} 018^{\mathrm{T}}$ representing candidate species I and II (Table 1), respectively, were used for cross-nodulation tests with 11 leguminous plant species: Pisum sativum, Phaseolus vulgaris, Vigna unguiculata, Glycine max, Leucaena leucocephala, Macroptilium atropurpureum, Galega officinalis, Astragalus sinicus, Medicago sativa, Trifolium repens and Lotus corniculatus. Seed treatment and inoculation were performed using the standard method of Vincent (1970).

\section{RESULTS AND DISCUSSION}

A polyphasic approach has been suggested to accurately define taxonomic groups among rhizobia (de Lajudie et al., 1998). Of the available methods, $16 \mathrm{~S}$ rRNA gene sequencing is the most reliable for genus identification. Species identification is normally based upon both genetic or genomic comparison and phenotypic characterization. Genetic distance of 0.5 in multilocus enzyme electrophoresis (Martínez-Romero et al., 1991; Wang et al., 1999), $70 \%$ DNA-DNA relatedness in DNA hybridization (Graham et al., 1991; Wayne et al., 1987) and $80 \%$ similarity in numerical taxonomy (Chen et al., 1991; Gao et al., 1994) have been used or suggested as reference borders for species differentiation. These values are used in relevant analyses in this work. 
Table 1. Strains used in this study

Rhizobial strains isolated from Astragalus adsurgens, reference strains and their grouping results in numerical taxonomy and in analyses of molecular biology. The groups of AFLP and rep-PCR and genotypes of $16 \mathrm{~S}$ and $23 \mathrm{~S}$ rRNA were defined in a previous work (Gao et al., 2001).

\begin{tabular}{|c|c|c|c|c|c|}
\hline Isolate or strain & $\begin{array}{l}\text { Cluster in } \\
\text { numerical } \\
\text { taxonomy }\end{array}$ & \multicolumn{2}{|c|}{ Group of } & \multicolumn{2}{|c|}{ Genotype of rRNA } \\
\hline SDW012 & 2 & 7 & 10 & & \\
\hline SDW014 ${ }^{\mathrm{T}}$ & 2 & 7 & 10 & 3 & 3 \\
\hline SDW048 & 2 & 11 & 6 & 3 & 3 \\
\hline SDW020, SDW022, SDW028, SDW030, SDW065, SDW067 & 2 & 11 & 7 & & \\
\hline SDW068 & 2 & 11 & 7 & 3 & 3 \\
\hline SDW043, SDW047 & 2 & 11 & 9 & & \\
\hline SDW044 & 2 & 11 & 9 & 3 & 3 \\
\hline \multicolumn{6}{|l|}{ Candidate species II (Mesorhizobium temperatum) } \\
\hline SDW015 & 1 & 7 & 3 & & \\
\hline SDW016 & 1 & 7 & 3 & 5 & 5 \\
\hline $\mathrm{SDW} 018^{\mathrm{T}}$ & 11 & 7 & 3 & 5 & 5 \\
\hline SDW029, SDW039, SDW050, SDW055 & 11 & 10 & 3 & & \\
\hline SDW026, SDW038, SDW049 & 11 & 10 & 3 & 5 & 5 \\
\hline NM026 & 11 & 17 & 3 & 5 & 5 \\
\hline NM300 & 11 & 17 & 3 & & \\
\hline \multicolumn{6}{|l|}{ Candidate species III (Agrobacterium sp.) } \\
\hline $\begin{array}{l}\text { SDW002, SDW003, SDW004, SDW005, SDW011, R084, SDW041, SDW051, } \\
\text { SDW053, SDW054, SDW059, SDW063, SDW069, SDW070, SH394, SH395 }\end{array}$ & 6 & 14 & 31 & & \\
\hline SH286 & 1 & 29 & 9 & 4 & 8 \\
\hline SDW013 & 2 & 7 & 15 & & \\
\hline SDW046 & 2 & 1 & 11 & 4 & 7 \\
\hline SDW040 & 2 & 2 & 5 & 4 & 7 \\
\hline SDW27 & 2 & 28 & 21 & 4 & 7 \\
\hline SDW017 & 2 & 9 & 29 & 4 & 4 \\
\hline SDW023, SDW066 & 3 & 10 & 3 & & \\
\hline SDW045 & Single & 31 & 14 & 7 & 9 \\
\hline SH138 & 4 & 5 & 24 & 5 & 5 \\
\hline SH152 & 4 & 7 & 6 & 3 & 3 \\
\hline SDW071 & 4 & 11 & 2 & & \\
\hline SDW074 & 11 & 12 & 6 & 3 & 3 \\
\hline \multicolumn{6}{|l|}{ Rhizobium spp. } \\
\hline SDW027 & 5 & 7 & 10 & 9 & 11 \\
\hline SDW062 & 5 & 12 & 11 & 13 & 15 \\
\hline SX211a & 5 & 21 & 33 & 8 & 10 \\
\hline
\end{tabular}


Table 1. cont.

\begin{tabular}{|c|c|c|c|c|c|}
\hline \multirow[t]{2}{*}{ Isolate or strain } & \multirow{2}{*}{$\begin{array}{l}\text { Cluster in } \\
\text { numerical } \\
\text { taxonomy }\end{array}$} & \multicolumn{2}{|c|}{ Group of } & \multicolumn{2}{|c|}{ Genotype of rRNA } \\
\hline & & AFLP & rep-PCR & $16 S$ & $23 S$ \\
\hline NM179 & 5 & 22 & 36 & 21 & 21 \\
\hline SDW058 & 5 & 25 & 30 & 12 & 14 \\
\hline SDW042 & 6 & 16 & 26 & & \\
\hline SDW056 & 6 & 23 & 20 & 19 & 20 \\
\hline SDW057 & 6 & 23 & 20 & & \\
\hline SDW16 & 6 & 7 & 34 & 11 & 13 \\
\hline $\mathrm{N} 211$ & 6 & 27 & 7 & & \\
\hline NM277, NM366 & 8 & 3 & 32 & & \\
\hline \multicolumn{6}{|l|}{ Reference strains } \\
\hline Rhizobium sp. (Astragalus) CA8593 & 9 & 6 & 1 & 9 & 11 \\
\hline Rhizobium sp. (Astragalus) CA8561 & 9 & 6 & 1 & & \\
\hline Rhizobium sp. (Astragalus) X59 & 9 & 7 & 1 & 20 & 11 \\
\hline Rhizobium sp. (Astragalus) JL84 & 7 & 27 & 34 & 11 & 13 \\
\hline Rhizobium sp. (Astragalus) SX042 & 7 & 27 & 7 & 11 & 13 \\
\hline Rhizobium leguminosarum USDA $2370^{\mathrm{T}}$ & 8 & 26 & 12 & 14 & 16 \\
\hline Rhizobium leguminosarum 127K17 & 8 & 19 & 8 & & \\
\hline Sinorhizobium meliloti USDA $1002^{\mathrm{T}}$ & 12 & 20 & 22 & 17 & 19 \\
\hline Sinorhizobium meliloti 102F28 & 12 & 20 & 22 & & \\
\hline
\end{tabular}

\section{Phenotypic characterization and numerical taxonomy}

The results of numerical taxonomy are summarized in Fig. 1 and Table 1. Most of the strains tested are grouped into 12 clusters at a similarity level of $83 \%$. The others are single strains. Among these, the clusters 8, 10 and 12 correspond to Rhizobium leguminosarum, Mesorhizobium huakuii and Sinorhizobium meliloti, respectively. Clusters 7 and 9 are composed of the reference strains from two unnamed rhizobial groups isolated from Astragalus species (Wang \& Chen, 1996). Clusters 1 to 6 and 11 consist only of strains from Astragalus adsurgens, of which, clusters 2, 6 and 11 are the largest. The 31 strains in cluster 2 and the 11 strains in cluster 11 form single colonies of less than $1 \mathrm{~mm}$ in diameter within 7-10 days and produce acid on YMA medium. Cluster 6 contains 26 strains that form single colonies of $2-3 \mathrm{~mm}$ in diameter within 3-5 days and produce acid on YMA medium.

It seems that the clusters defined by similarity values of more than $83 \%$ in numerical taxonomy are more conservative than are the groups defined by rep-PCR fingerprinting, AFLP fingerprinting, and 16S rRNA and 23S
rRNA PCR-RFLP (Gao et al., 2001) and are largely in good agreement with the rRNA RFLP. All the main clusters based on numerical taxonomy contain strains corresponding to several groups of AFLP or rep-PCR, and to more than one genotype of rRNA. For instance, cluster 2 includes Mesorhizobium strains belonging to AFLP groups 7, 11, 1, 2, 28 and 9; rep-PCR groups 10, 15, 2, 6, 7, 9, 13, 16, 11, 5, 21 and 29; and three genotypes of rRNA. Strains in AFLP group 7 (Gao et al., 2001) are found in numerical taxonomy clusters $1,2,4,5,6,9,10$ and 11 . These results suggest that AFLP and rep-PCR analyses are more valuable for revealing genetic diversity than for estimating taxonomic relationships. In order to clarify further the genetic relationships among strains within the larger numerical taxonomy groups, the full-length 16S rRNA and partial $g \ln A$ gene were sequenced for some strains.

\section{5 rRNA and gInA gene sequencing}

Full-length $(\sim 1500 \mathrm{bp}) 16 \mathrm{~S}$ rRNA genes were sequenced for strains SDW014 ${ }^{\mathrm{T}}, \mathrm{SDW}_{018^{\mathrm{T}}}$ and SDW052, chosen to represent the three main numerical clusters $(2,11$ and 6$)$ (Table 1). The phylogenetic relationships of these sequences 


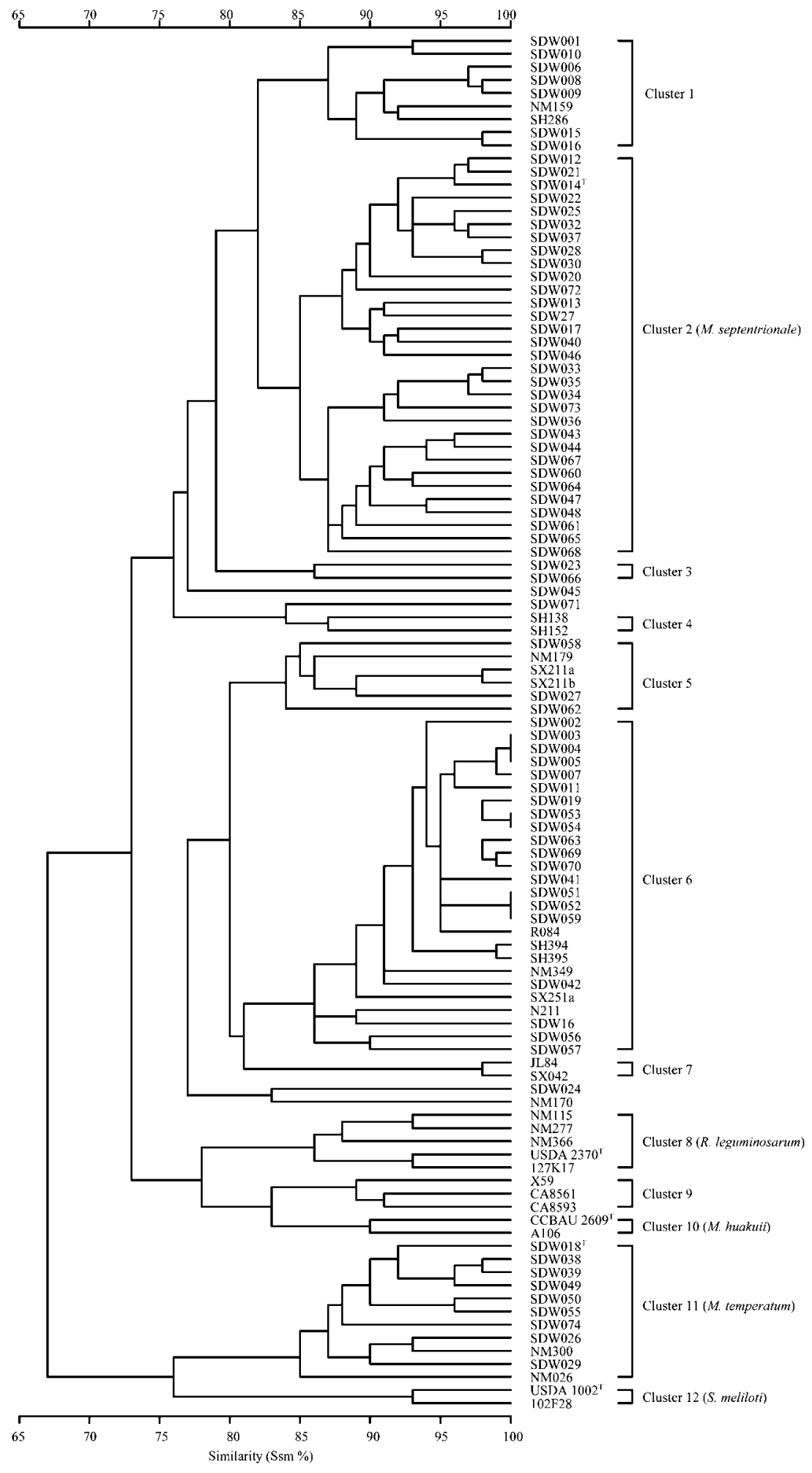

Fig. 1. Dendrogram showing the phenotypic similarities among the rhizobial isolates from Astragalus adsurgens in China. Clustering analysis was performed using the UPGMA method (Sneath \& Sokal, 1973).

(Fig. 2) are in good agreement with those estimated from the 900 bp partial $16 \mathrm{~S}$ rRNA gene sequences determined previously (Gao et al., 2001), which clearly showed that strains SDW014 ${ }^{\mathrm{T}}$ and SDW018 ${ }^{\mathrm{T}}$ are related to Mesorhizobium species. Strain SDW014 ${ }^{\mathrm{T}}$ shares $99 \%$ sequence identity with Mesorhizobium amorphae, Mesorhizobium huakuii and Mesorhizobium plurifarium, which form a subgroup within the genus Mesorhizobium. Strain SDW018 is closely related to Mesorhizobium mediterraneum (99\% sequence identity). Strain SDW052 is related to Agrobacterium tumefaciens and Agrobacterium rubi, with 99 and $97 \%$ sequence identity, respectively. 


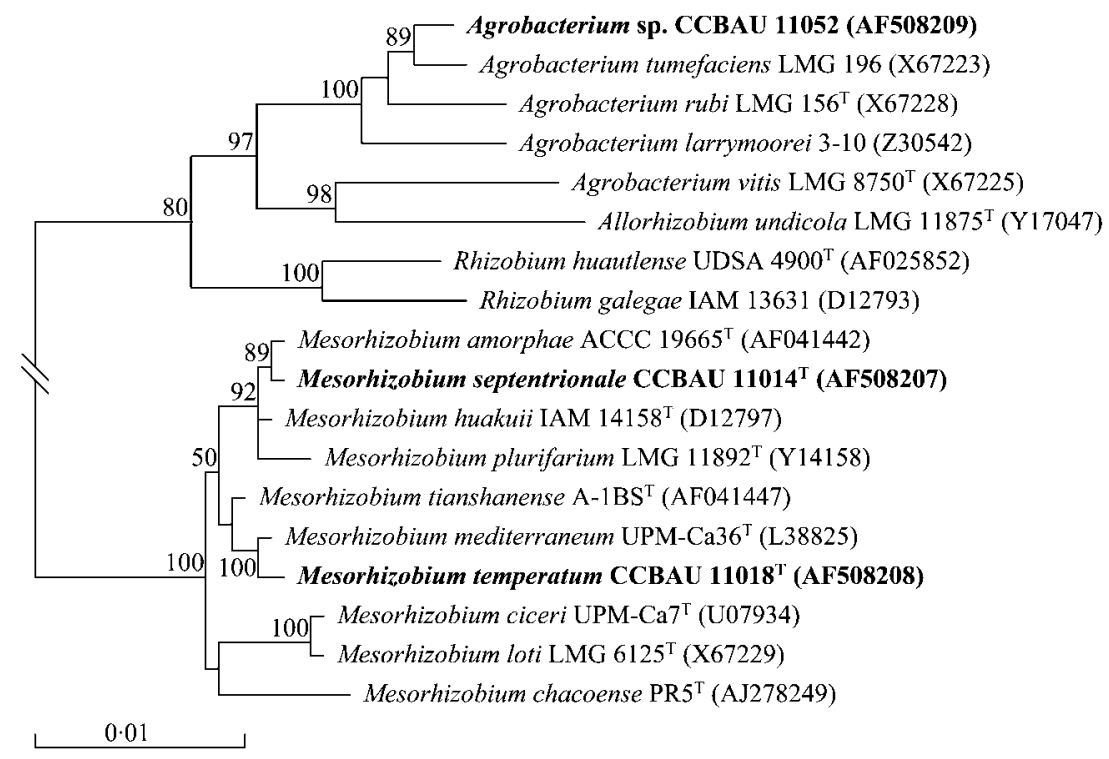

Fig. 2. Simplified phylogenetic tree (complete tree is available in IJSEM Online) showing the phylogenetic relationships among Mesorhizobium septentrionale, Mesorhizobium temperatum and the Agrobacterium group identified in this work and some related bacteria in the $\alpha$-Proteobacteria. The tree was constructed from full-length sequences of the $16 \mathrm{~S}$ rRNA genes using the neighbour-joining method in the CLUSTAL_X package (Thompson et al., 1997). Bootstrap values (1000 replicates) greater than $60 \%$ are shown on the appropriate nodes. Bar, 0.01\% nucleotide divergence.

Recent studies have used other core metabolism genes to investigate the reliability of $16 \mathrm{~S}$ rRNA gene-based species definitions among rhizobia (Turner \& Young, 2000; Gaunt et al., 2001). In this study, PCR amplification and sequencing of the partial $g \ln A$ gene was undertaken. The 11 obtained sequences have been deposited in the GenBank/EMBL/DDBJ databases under accession numbers AJ579875-AJ579885, which are from the representatives of clusters 2 (SDW014 ${ }^{\mathrm{T}}$, SDW017, SDW037 and SDW040), 11 (SDW018 $^{\mathrm{T}}$ and NM026) and 6 (SDW052 and NM349) identified by numerical taxonomy and also for representatives of two minor clusters, 1 (SDW010) and 5 (SDW058 and SX211a). The relationships inferred from these sequences are in agreement with the earlier 16S rRNA gene analysis (a supplementary phylogenetic tree is available in IJSEM Online). The two cluster 11 strains, $\mathrm{SDW} 018^{\mathrm{T}}$ and NM026, have identical sequences that are most closely related to Mesorhizobium mediterraneum. The $g \ln A$ sequencing results also support the clustering of strains in cluster 6 and their affiliation with Agrobacterium species. The cluster 2 sequences are more divergent but are all Mesorhizobium-like. Strains SDW014 ${ }^{\mathrm{T}}$ and SDW037 group together and are not closely related to any other described type strain for which a sequence is available. The two other cluster 2 strains, SDW040 and SDW017, are not closely affiliated with strain SDW014 ${ }^{\mathrm{T}}$ or SDW037, or with any of the previously described Mesorhizobium type strain sequences. Of the strains examined from the minor numerical taxonomy clusters, SDW010 (cluster 1) is closely related to Mesorhizobium tianshanense, and SDW058 and SX211a (cluster 5) are probably Rhizobium spp. that are unrelated to any described type strain. All these findings corroborate the earlier partial 16S rRNA gene data of Gao et al. (2001).

Based upon the numerical taxonomy and the sequencing data of this work and those of rep-PCR fingerprinting, AFLP fingerprinting, 16S rRNA and 23S rRNA PCR-RFLP from an earlier study (Gao et al., 2001), we defined three candidate species (I, II and III) among the strains from Astragalus adsurgens (Table 1). Twenty-seven of the 31 strains in cluster 2 (Fig. 1) were defined as candidate species I. Twenty-four of the 27 strains in candidate species I were in AFLP group 11 and three strains were in AFLP group 7 but they shared the same rRNA genotype. This indicates that the strains in candidate species I are highly related both in phenotypic and in genotypic characteristics. The rep-PCR results (Gao et al., 2001), which clustered these 27 strains into eight groups, indicate that there is genetic diversity within the candidate species I strains. Four strains in cluster 2, SDW040, SDW046, SDW017 and SDW27, were not included in candidate species I because they had different AFLP patterns and 16S rRNA and 23S rRNA genotypes, and did not group with SDW014 ${ }^{\mathrm{T}}$ in either partial 16S (Gao et al., 2001) or $g \ln A$ phylogenies.

Candidate species II consisted of 10 of the 11 isolates within cluster 11 and 2 isolates in cluster 1 (Fig. 1), which have the same rRNA genotype. They belonged to a single rep-PCR group and three AFLP groups (Gao et al., 2001). One strain, SDW074, of cluster 11 was not included in candidate species II because its $16 \mathrm{~S}$ rRNA and 23S rRNA genotypes (Table 1) are identical to the strains of candidate species I. This strain will require more detailed analysis to determine its true taxonomic position.

Candidate species III is composed of 19 of the 26 isolates in numerical taxonomy cluster 6 (Fig. 1). Seven strains, SDW16, SX251a, NM349, SDW042, SDW056, SDW057 and N211, were not included in candidate species III mainly due to their different rRNA genotypes. All 19 strains in candidate species III belong to rep-PCR group 31 and AFLP groups 14 and 15 (Gao et al., 2001), suggesting that they are highly related both phenotypically and genetically. 
Table 2. DNA-DNA relatedness among strains representing candidate species I, II and III and the type strains of some recognized species in the genera Mesorhizobium and Agrobacterium

Candidate species I, Mesorhizobium septentrionale (SDW014 ${ }^{\mathrm{T}}$ ); candidate species II, Mesorhizobium temperatum $\left(\mathrm{SDW}_{018}^{\mathrm{T}}\right)$; candidate species III, Agrobacterium sp. (SDW052).

\begin{tabular}{|c|c|c|c|}
\hline \multirow[t]{2}{*}{ Type or reference strain } & \multicolumn{3}{|c|}{ DNA relatedness (\%) with strain: } \\
\hline & SDW014 $^{\mathrm{T}}$ & SDW018 $^{\mathrm{T}}$ & SDW052 \\
\hline Mesorhizobium amorphae ACCC $19665^{\mathrm{T}}$ & $13 \cdot 3$ & $24 \cdot 1$ & \\
\hline Mesorhizobium chacoense LMG $19008^{\mathrm{T}}$ & $25 \cdot 5$ & $28 \cdot 3$ & \\
\hline Mesorhizobium plurifarium LMG $11892^{\mathrm{T}}$ & $25 \cdot 5$ & $11 \cdot 3$ & \\
\hline Mesorhizobium huakuii CCBAU $2609^{\mathrm{T}}$ & $32 \cdot 9$ & $46 \cdot 2$ & \\
\hline Mesorhizobium ciceri USDA $3383^{\mathrm{T}}$ & $16 \cdot 8$ & $32 \cdot 9$ & \\
\hline Mesorhizobium loti NZP $2213^{\mathrm{T}}$ & $31 \cdot 1$ & $29 \cdot 9$ & \\
\hline Mesorhizobium mediterraneum USDA $3392^{\mathrm{T}}$ & $28 \cdot 9$ & $47 \cdot 1$ & \\
\hline Mesorhizobium tianshanense A-1BS ${ }^{\mathrm{T}}$ & $23 \cdot 7$ & $45 \cdot 8$ & \\
\hline Agrobacterium tumefaciens IAM $13129^{\mathrm{T}}$ & & & $25 \cdot 2$ \\
\hline Agrobacterium rubi IAM $13569^{\mathrm{T}}$ & & & $4 \cdot 3$ \\
\hline SDW014 ${ }^{\mathrm{T}}$ & 100 & $32 \cdot 1$ & \\
\hline SDW012 & $87 \cdot 6$ & & \\
\hline SDW034 & $81 \cdot 5$ & & \\
\hline SDW018 ${ }^{\mathrm{T}}$ & & 100 & \\
\hline SDW016 & & $92 \cdot 9$ & \\
\hline SDW017 & 0 & & \\
\hline SDW046 & 0 & & \\
\hline
\end{tabular}

Comparative analyses of representative $16 \mathrm{~S}$ rRNA and partial $g \ln A$ gene sequences indicate that these strains are Agrobacterium spp. most closely related to Agrobacterium tumefaciens (Fig. 2). The failure of these strains to nodulate Astragalus adsurgens indicates either that they have lost their symbiotic genes rapidly during the isolation procedure or that they were never symbiotic (Gao et al., 2001). The identification of non-symbiotic Agrobacterium strains from Astragalus adsurgens nodules showed again that non-symbiotic strains may occupy some nodules. Similar observations have been reported by Tan et al. (1999) and by de Lajudie et al. (1999). Further work is needed to clarify the genetic relationships between the candidate species III strains and pathogenic species within the genus Agrobacterium.

\section{DNA base composition and DNA-DNA hybridization}

To date, eight species have been described within genus Mesorhizobium (de Lajudie et al., 1998; Jarvis et al., 1997; Velázquez et al., 2001). All these species share more than $97 \%$ sequence similarity among their 16S rRNA genes (de Lajudie et al., 1998) and their definition relies mainly on the genetic and phenotypic grouping results, including DNA-DNA hybridization. Strains SDW014 ${ }^{\mathrm{T}}$, SDW018 ${ }^{\mathrm{T}}$ and SDW052 representing the candidate species I, II and III, respectively, were chosen for determination of DNA base composition and for DNA-DNA hybridization with the type strains of Mesorhizobium and Agrobacterium species. The DNA G $+\mathrm{C}$ content of SDW014 ${ }^{\mathrm{T}}$ and SDW $018^{\mathrm{T}}$ was
$59 \cdot 4$ and $65 \cdot 1 \%$, respectively. The results of DNA-DNA hybridization are shown in Table 2. DNA-DNA relatedness values of greater than $80 \%$ are detected among the strains within each of the candidate species I and II. Among SDW014 ${ }^{\mathrm{T}}, \mathrm{SDW} 018^{\mathrm{T}}$ and the type strains of Mesorhizobium species, the DNA-DNA relatedness ranges from $11 \cdot 3$ to $47 \cdot 1 \%$. Strain SDW052 has DNA-DNA relatedness of $25 \cdot 2$ and $4.3 \%$ with Agrobacterium tumefaciens and Agrobacterium rubi, respectively. These values clearly indicate that candidate species I and II are genomic species distinct from each other and from the type strains for defined Mesorhizobium species. The very low DNA-DNA relatedness between SDW014 ${ }^{\mathrm{T}}$ and SDW017 and SDW046 supports the exclusion of the latter two and related strains from candidate species I (Table 1).

As well as the different genotypes of rRNA, the utilization of fructose, glucose, inositol, malate, succinate, sucrose and turanose as carbon source can differentiate candidate species I from candidate species II. These two candidate species also can be differentiated from other Mesorhizobium species by their geographical origins and the natural host origins. Based upon the proposed standards for describing novel species (Graham et al., 1991; Wayne et al., 1987) and the results presented here and in previous work (Gao et al., 2001), we believe that candidate species I and II represent two novel species within the genus Mesorhizobium. Since all the strains are from the temperate region in northern China, we propose the names Mesorhizobium septentrionale sp. nov. and Mesorhizobium temperatum sp. nov. for candidate species I and II, respectively. 


\section{Symbiotic properties and nodA gene sequencing}

Host range is an important feature for the root- and/or stem-nodule bacteria and cross-nodulation with the selected hosts is required for the description of novel rhizobial species (Graham et al., 1991). The cross-nodulation results showed that strain SDW014 ${ }^{\mathrm{T}}$ could nodulate Phaseolus vulgaris, Glycine max, Leucaena leucocephala, Macroptilium atropurpureum and Lotus corniculatus, but not Pisum sativum, Vigna unguiculata, Galega officinalis, Astragalus sinicus, Medicago sativa or Trifolium repens. Strain SDW018 ${ }^{\mathrm{T}}$ could nodulate Phaseolus vulgaris, Vigna unguiculata, Glycine max, Leucaena leucocephala, Medicago sativa and Lotus corniculatus, but not Pisum sativum, Macroptilium atropurpureum, Galega officinalis, Astragalus sinicus or Trifolium repens. These results indicated that the type strains for the two novel species have different nodulation spectrums. This difference may be explained by the sequencing results of the nodulation genes.

Different rhizobial species have been isolated and subsequently recognized from Astragalus hosts, including Astragalus adsurgens, as mentioned in the Introduction. This conclusion has been substantiated in the present study, since these rhizobia also have diverse phenotypic characteristics by numerical taxonomy. However, diversity of the symbiotic gene, nodA, superficially appears to be markedly less than measures of chromosomal diversity. Most of the $\operatorname{nod} A$ sequences identified are most similar to that described for the type strain of Mesorhizobium tianshanense even though the novel isolates belong to different species and even to different genera (Fig. 3); for example, nodA of the proposed type strain of Mesorhizobium temperatum, SDW $018^{\mathrm{T}}$, differs from that of Mesorhizobium tianshanense at one synonymous site. Similarly, the $\operatorname{nodA}$ sequences of SDW037 (Mesorhizobium septentrionale), SDW062 (Mesorhizobium temperatum) and SX211a (unknown Rhizobium sp.) are also closely related to the Mesorhizobium tianshanense sequence (Fig. 3). These results might suggest that Astragalus adsurgens is symbiotically fastidious (has restricted requirements of the Nod factor signals for nodulation) but that the symbiotype (defined by symbiotic gene composition) functions in a range of rhizobial genetic backgrounds. The nodA sequence from SDW014 ${ }^{\mathrm{T}}$ is considerably divergent relative to the other nodA sequences obtained from Astragalus adsurgens (Fig. 3) and is unrelated to any other described nodA sequence in the databases. Whilst the host ranges of SDW014 ${ }^{\mathrm{T}}$ and $\mathrm{SDW}_{018^{\mathrm{T}}}$ differ, $\operatorname{nodA}$ is only one component that contributes to the host range limits of each symbiotype. It is therefore necessary to investigate more of the symbiotic genes from Astragalus adsurgens strains to better understand the ecological and evolutionary relationships of these particular rhizobial symbionts. Astragalus adsurgens has been successfully planted in different regions in China as soil cover and foliage. The ability of the dominant symbiotype, associated with Astragalus adsurgens, to function in diverse chromosomal backgrounds and to nodulate a range of legumes may help to explain why the plant has been grown successfully over such a wide area.

\section{Description of Mesorhizobium septentrionale sp. nov.}

Mesorhizobium septentrionale (sep.ten.tri.o.na'le. L. neut. adj. septentrionale northern, implying that the strains were isolated from the northern parts of China).

Gram-negative, aerobic, non-spore-forming rods. Colonies on YMA medium are circular, convex, translucent and have a diameter of $1 \mathrm{~mm}$ within $7-10$ days at $28^{\circ} \mathrm{C}$. Generation times are 6-9 h in PY broth (Wang et al., 1999). Can use fructose, glucose, inositol, malate, maltose, D-mannose, melibiose, sodium succinate, D-sorbitol, sucrose, trehalose and turanose as sole carbon sources, and use hypoxanthine, L-isoleucine, L-phenylalanine and D-threonine as sole nitrogen sources. All strains have been deposited in the Culture Collection of China Agricultural University (CCBAU), China and in the Culture Collection of Helsinki University (HAMBI), Finland.

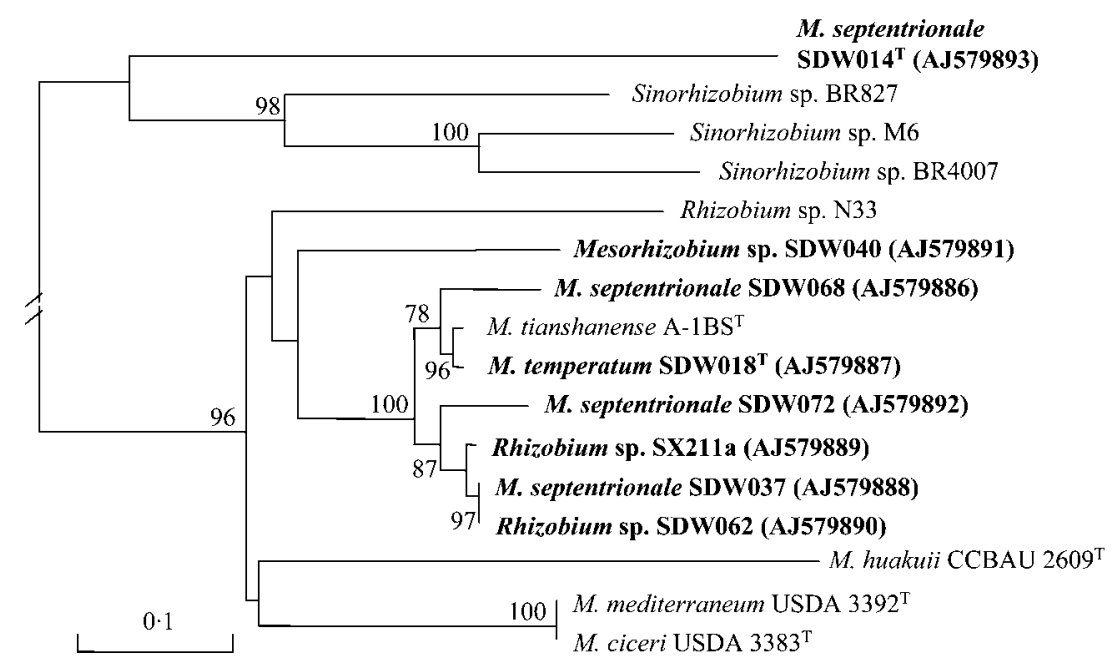

Fig. 3. Simplified neighbour-joining phylogeny estimated from partial nodA gene sequences using the K2P evolutionary model in CLUSTAL_X. Bootstrap values (1000 replicates) greater than $60 \%$ are shown on the appropriate nodes. All sequences, other than those shown in bold, were taken from Zhang et al. (2000). 
The type strain is SDW014 ${ }^{\mathrm{T}}\left(=\mathrm{CCBAU} 11014^{\mathrm{T}}=\right.$ HAMBI $\left.2582^{\mathrm{T}}\right)$; it has the characteristics described for the species. The G $+\mathrm{C}$ content of the genomic DNA of the type strain is $59 \cdot 4 \%$.

\section{Description of Mesorhizobium temperatum sp. nov.}

Mesorhizobium temperatum (tem.pe.ra'tum. L. neut. adj. temperatum temperate, implying that the strains were isolated from temperate zones).

Gram-negative, aerobic, non-spore-forming rods. Colonies on YMA medium are circular, convex, translucent and have a diameter of $1 \mathrm{~mm}$ within $7-10$ days at $28^{\circ} \mathrm{C}$. The generation times are 5-9 h in PY broth (Wang et al., 1999). Cannot use fructose, glucose, inositol, malate, maltose, Dmannose, melibiose, sodium succinate, D-sorbitol, sucrose, trehalose or turanose as sole carbon sources, but can use hypoxanthine and D-threonine as sole nitrogen sources. All the strains have been deposited in the Culture Collection of China Agricultural University (CCBAU), China and in the Culture Collection of Helsinki University (HAMBI), Finland.

The type strain is SDW $018^{\mathrm{T}}\left(=\mathrm{CCBAU} 11018^{\mathrm{T}}=\right.$ HAMBI $\left.2583^{\mathrm{T}}\right)$; it has the characteristics described for the species. The $\mathrm{G}+\mathrm{C}$ content of the genomic DNA of the type strain is $65 \cdot 1 \%$

\section{ACKNOWLEDGEMENTS}

This work was supported financially by EU-INCO contract no. IC18CT96-0103 and by the Natural Science Foundation of China project no. 2001CB108905. We are grateful to H. G. Trüper for suggesting the names of the two novel species and to Mr Q. Chen for his technical support.

\section{REFERENCES}

Allen, O. N. \& Allen, E. K. (1981). The Leguminoseae: a Source Book of Characteristics, Uses, and Nodulation. Madison, WI: University of Wisconsin Press.

Chen, W. X., Yan, G. H. \& Li, J. L. (1988). Numerical taxonomic study of fast-growing soybean rhizobia and a proposal that Rhizobium fredii be assigned to Sinorhizobium gen. nov. Int J Syst Bacteriol 38, 392-397.

Chen, W. X., Li, G. S., Qi, Y. L., Wang, E. T., Yuan, H. L. \& Li, J. L. (1991). Rhizobium huakuii sp. nov. isolated from the root nodules of Astragalus sinicus. Int J Syst Bacteriol 41, 275-280.

Chen, W. X., Wang, E. T., Wang, S. Y., Li, Y. B., Chen, X. Q. \& Li, Y. (1995). Characteristics of Rhizobium tianshanense sp. nov., a moderately and slowly growing root nodule bacterium isolated from an arid saline environment in Xinjiang, People's Republic of China. Int J Syst Bacteriol 45, 153-159.

Chen, W.-X., Tan, Z.-Y., Gao, J.-L., Li, Y. \& Wang, E.-T. (1997). Rhizobium hainanense sp. nov., isolated from tropical legumes. Int J Syst Bacteriol 47, 870-873. de Lajudie, P., Willems, A., Nick, G. \& 9 other authors (1998). Characterization of tropical tree rhizobia and description of Mesorhizobium plurifarium sp. nov. Int J Syst Bacteriol 48, 369-382.

de Lajudie, P., Willems, A., Nick, G. \& 8 other authors (1999). Agrobacterium bv. 1 strains isolated from tropical legumes. Syst Appl Microbiol 22, 119-132.

De Ley, J., Cattoir, H. \& Reynaerts, A. (1970). Quantitative measurement of DNA hybridization from renaturation rates. Eur J Biochem 12, 133-142.

Gao, J. L., Sun, J. G., Li, Y., Wang, E. T. \& Chen, W. X. (1994). Numerical taxonomy and DNA relatedness of tropical rhizobia isolated from Hainan Province, China. Int J Syst Bacteriol 44, 151-158.

Gao, J. L., Terefework, Z. D., Chen, W. X. \& Lindström, K. (2001). Genetic diversity of rhizobia isolated from Astragalus adsurgens growing in different geographical regions of China. J Biotechnol 91, 155-168.

Gaunt, M. W., Turner, S. L., Rigottier-Gois, L., Lloyd-Macgilp, S. A. \& Young, J. P. W. (2001). Phylogenies of atpD and recA support the small subunit rRNA-based classification of rhizobia. Int J Syst Evol Microbiol 51, 2037-2048.

Graham, P. H., Sadowsky, M. J., Keyser, H. H. \& 8 other authors (1991). Proposed minimal standards for the description of new genera and species of root- and stem-nodulating bacteria. Int J Syst Bacteriol 41, 582-587.

Guo, X. W., Zhang, X. X., Zhang, Z. M. \& Li, F. D. (1999). Characterization of Astragalus sinicus rhizobia by restriction fragment length polymorphism analysis of chromosomal and nodulation genes regions. Curr Microbiol 39, 358-364.

Hurek, T., Wagner, B. \& Reinhold-Hurek, B. (1997). Identification of $\mathrm{N}_{2}$-fixing plant- and fungus-associated Azoarcus species by PCRbased genomic fingerprints. Appl Environ Microbiol 63, 4331-4339.

Jarvis, B. D. W., van Berkum, P., Chen, W. X., Nour, S. M., Fernandez, M. P., Cleyet-Marel, J. C. \& Gillis, M. (1997). Transfer of Rhizobium loti, Rhizobium huakuii, Rhizobium ciceri, Rhizobium mediterraneum, and Rhizobium tianshanense to Mesorhizobium gen. nov. Int J Syst Bacteriol 47, 895-898.

Laguerre, G., van Berkum, P., Amarger, N. \& Prevost, D. (1997). Genetic diversity of rhizobial symbionts isolated from legume species within genera Astragalus, Oxytropis, and Onobrychis. Appl Environ Microbiol 63, 4748-4758.

Li, J., Yu, L., Li, N. \& Wang, H. (2000). Astragalus mongholicus and Angelica sinensis compound alleviates nephritic hyperlipidemia in rats. Chin Med J 113, 310-314.

Marmur, J. (1961). A procedure for the isolation of DNA from microorganisms. J Mol Biol 3, 208-218.

Marmur, J. \& Doty, P. (1962). Determination of the base composition of deoxyribonucleic acid from its thermal denaturation temperature. J Mol Biol 5, 109-118.

Martínez-Romero, E., Segovia, L., Mercante, F. M., Franco, A. A., Graham, P. \& Pardo, M. A. (1991). Rhizobium tropici, a novel species nodulating Phaseolus vulgaris L. beans and Leucaena sp. trees. Int J Syst Bacteriol 41, 417-426.

Nagasawa, H., Watanabe, K., Yoshida, M. \& Inatomi, H. (2001). Effects of gold banded lily (Lilium auratum Lindl) or Chinese milk vetch (Astragalus sinicus $\mathrm{L}$ ) on spontaneous mammary tumourigensis in SHN mice. Anticancer Res 21, 2323-2328.

Page, R. D. (1996). TreeView: an application to display phylogenetic trees on personal computers. Comput Appl Biosci 12, 357-358.

Peng, G. X., Tan, Z. Y., Wang, E. T., Reinhold-Hurek, B., Chen, W. F. \& Chen, W. X. (2002). Identification of isolates from soybean nodules in Xinjiang Region as Sinorhizobium xinjiangense and genetic 
differentiation of S. xinjiangense from Sinorhizobium fredii. Int J Syst Evol Microbiol 52, 457-462.

Shon, Y. H., Kim, J. H. \& Nam, K. S. (2002). Effects of Astragali radix extract on lipopolysaccharide-induced inflammation in human amnion. Biol Pharm Bull 25, 77-80.

Sneath, P. H. A. \& Sokal, R. R. (1973). Numerical Taxonomy. The Principles and Practices of Numerical Classification. San Francisco: W. H. Freeman.

Sriprang, R., Hayashi, M., Yamashita, M., Ono, H., Saeki, K. \& Murooka, Y. (2002). A novel bioremediation system for heavy metals using the symbiosis between leguminous plant and genetically engineered rhizobia. J Biotechnol 99, 279-293.

Sullivan, J. T., Eardly, B. D., van Berkum, P. \& Ronson, C. W. (1996). Four unnamed species of nonsymbiotic rhizobia isolated from the rhizosphere of Lotus corniculatus. Appl Environ Microbiol 62, 2818-2825.

Tan, Z. Y., Wang, E. T., Peng, G. X., Zhu, M. E., Martínez-Romero, E. $\&$ Chen, W. X. (1999). Characterization of bacteria isolated from wild legumes in the north-western regions of China. Int J Syst Bacteriol 49, 1457-1469.

Thompson, J. D., Gibson, T. J., Plewniak, F., Jeanmougin, F. \& Higgins, D. G. (1997). The CLUSTAL_X windows interface: flexible strategies for multiple sequence alignment aided by quality analysis tools. Nucleic Acids Res 25, 4876-4882.

Turner, S. L. \& Young, J. P. W. (2000). The glutamine synthetases of rhizobia: phylogenetics and evolutionary implications. Mol Biol Evol 17, 309-319.
Velázquez, E., Igual, J. M., Willems, A. \& 9 other authors (2001). Mesorhizobium chacoense sp. nov., a novel species that nodulates Prosopis alba in the Chaco Arido region (Argentina). Int J Syst Evol Microbiol 51, 1011-1021.

Vincent, J. M. (1970). A Manual for the Practical Study of Root Nodule Bacteria. IBP Handbook no.15. Oxford: Blackwell Scientific.

Wang, S. Y. \& Chen, W. X. (1996). Numerical taxonomy and DNA relatedness of rhizobia isolated from Astragalus spp. In Diversity and Taxonomy of Rhizobia, pp. 79-84. Edited by F. D. Li et al. Beijing: China Agricultural Scientech Press.

Wang, E. T., van Berkum, P., Sui, X. H., Beyene, D., Chen, W. X. \& Martínez-Romero, E. (1999). Diversity of rhizobia associated with Amorpha fruticosa isolated from Chinese soils and description of Mesorhizobium amorphae sp. nov. Int J Syst Bacteriol 49, 51-65.

Wayne, L. G., Brenner, D. J., Colwell, R. R. \& 9 other authors (1987). International Committee on Systematic Bacteriology. Report of the ad hoc committee on reconciliation of approaches to bacterial systematics. Int J Syst Bacteriol 37, 463-464.

Wdowiak, S. \& Malek, W. (2000). Numerical analysis of Astragalus cicer microsymbionts. Curr Microbiol 41, 142-148.

Xu, L. M., Ge, C., Cui, Z., Li, J. \& Fan, H. (1995). Bradyrhizobium liaoningense sp. nov., isolated from the root nodules of soybeans. Int J Syst Bacteriol 45, 706-711.

Zhang, X. X., Turner, S. L., Gao, X. W., Yang, H. J., Debelle, F., Yang, G. P., Denarie, J., Young, J. P. W. \& Li, F. D. (2000). The common nodulation genes of Astragalus sinicus rhizobia are conserved despite chromosomal diversity. Appl Environ Microbiol 66, 2988-2995. 